\title{
Chewing the fat with Mitchell A. Lazar
}

$T_{b}$ he ASCI is honoring Mitchell A. Lazar (Figure 1), Director of the Institute for Diabetes, Obesity, and Metabolism at the University of Pennsylvania, with the 2009 Stanley J. Korsmeyer Award. This award is presented annually by the ASCI to one of its members for outstanding contributions both to advancing understanding of a specific human disease and to mentoring future generations of researchers.

JCI: As you are being recognized for your contributions to understanding the transcriptional regulation of metabolism, what do you consider to be your greatest scientific accomplishment?

Lazar: I am proud of our work on thyroid hormone receptors, PPAR $\gamma$, and resistin. But at this point I'd have to say that my greatest scientific accomplishment has been the discovery and demystification of the nuclear receptor Rev-erb $\alpha$, which I discovered when I was a postdoc in Bill Chin's lab. When I started my lab at Penn, we were completely in the dark about its function. First we figured out that Reverb $\alpha$ binds specific DNA sequences by a novel mechanism that we later confirmed by structural analysis in collaboration with Fraydoon Rastinejad. Then we showed that Rev-erb $\alpha$ functions as a potent repressor of transcription by recruiting nuclear receptor corepressor 1 (NCoR). Next, in collaboration with Ramin Sheikhattar, we discovered that the corepressor forms a tight complex with histone deacetylase 3 (HDAC3), which requires this interaction for enzymatic activity. Most recently, we learned that activation of HDAC3 by the corepressor is required for normal circadian and molecular physiology. We also discovered that Rev-erb $\alpha$ is a receptor for molecular heme, which acts as a ligand that regulates the interaction between Rev-erb $\alpha$ and the corepressor to control circadian and metabolic pathways. So a very interesting picture is emerging on a Rev-erb $\alpha$ canvas that was blank when we began our work.

JCI: How do you manage to balance the demands of running a highly successful research laboratory and spending time in the clinic?

Lazar: That has evolved over the years. When I was a new assistant professor, I saw my own patients in the endocrinology clinic one half-day per week in addition to attending for a month on the endocrinology consult service. As my research program expanded and my administrative duties increased, I found that I no longer could devote the time needed to provide the absolute best care to my own patients. I miss the gratifying experience of helping an individual patient, which is something practicing endocrinologists get to do quite often!

JCI: What was the greatest obstacle to getting where you are now?

Lazar: There are many candidates! When I submitted my first NIH R01 grant in 1990 , the success rate was very low,

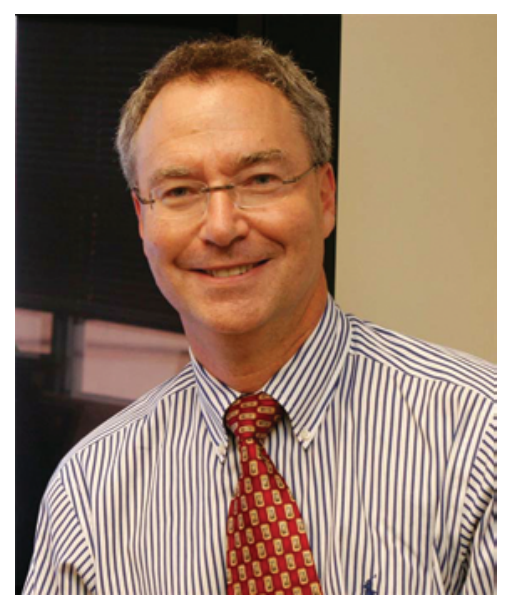

Figure 1

Mitchell A. Lazar will receive the 2009 ASCI Stanley J. Korsmeyer Award at the annual ASCI/AAP Joint Meeting, April 24-26, in Chicago.

maybe even lower than today. It was also more difficult than I thought it would be to establish my own reputation as a careful, creative, independent scientist. But perhaps the greatest obstacle was fighting a perception among colleagues in basic science departments that physician-scientists in departments of medicine were less serious and even dilettantish about basic research. That was overcome by hard work, strict quality standards, scientific productivity, and successful mentorship of younger scientists at the predoctoral and postdoctoral levels.
JCI: You received your $\mathrm{MD}$ and $\mathrm{PhD}$ in neuroscience. When and how did you become interested in endocrinology?

Lazar: I went to Stanford hoping to discover the biochemical basis of behavior. I really enjoyed my research on the mechanism of dopamine biosynthesis, but I began to doubt that understanding the biochemical basis of behavior was a tractable problem. At the same time, I loved the elegance of the feedback inhibition of tyrosine hydroxylase by its downstream product, dopamine. When I returned to medical school, I was struck by the importance of homeostastic mechanisms, which are at the heart of endocrinology as a discipline. So that was easy.

JCI: How can we best encourage and support young $\mathrm{MD} / \mathrm{PhDs}$ to follow a career course such as yours?

Lazar: This is an important issue, and over the years much has been written about this as well as the broader topic of fostering the physician-scientist. Here, I would emphasize that we need to be sure to pay attention to the entire life cycle of the physician-scientist. No one would argue that we need a pipeline of new investigators, who need to know that once they get in the game, their work can be sustained until retirement at an age which, thanks to biomedical science, will be significantly later in life than was typical for the previous generation. This will require the commitment of academic medical centers as well as the government and philanthropic organizations.

JCI: What other contributions to science are you proud of?

Lazar: I am proud to have mentored over 20 graduate students, including MD/PhD students, and about the same number of postdocs. They, and hopefully a few facts that it has been my privilege to uncover, are my legacy.

JCI: Which was more exciting: this award, or the Phillies winning the World Series?

Lazar: That's a tough one. I'm a big baseball fan and I've suffered through the Phillies' lack of success for the 20 years that I've lived in Philadelphia. The Phillies' victory may have been more exciting, but this recognition by my peers is much more personally satisfying.

\section{Karen Honey}

